\section{Clonal Propagation of Pink Ginger in Vitro}

\author{
Brian K.W. Chang' and Richard A. Criley ${ }^{2}$ \\ Department of Horticulture, University of Hawaii, Honolulu, HI 96822
}

Additional index words. Alpinia purpurata, clonal propagation, tissue culture, $N$-6-benzyladenine

Until the late 1980 s, there were basically five clones of red and pink gingers [Alpinia purpurata (Veill.) K. Schum.] (Criley, 1988a), with the majority of the production being the red A. purpurata (no cultivar name) and its pink cultivar Eileen McDonald.

These gingers primarily are propagated by division or by rooting aerial offshoots produced in the axils of the inflorescence bracts (Criley, 1988b). In 1985, however, Janet Ginoza, a commercial flower grower on the island of Oahu, found a seed pod on a plant of 'Eileen McDonald' and grew 20 seedlings from it (Hirano, 1991). The suspected pollen parent was the light-pink 'Jungle Queen'. While 'Eileen McDonald' produces aerial offshoots in the inflorescence, 'Jungle Queen' does not, and most of the progeny, which had contrasting pink bracts with darker pink margins, also did not produce aerial offshoots. Three new superior cultivars have been named and released. Their propagation is slow, however, since division of the rhizome mat is the only available method.

The objective of this research was to develop an in vitro multiplication system for rapid increase of these new clones.

Twenty bract axils (Fig. 1) with associated dormant buds were excised from an inflorescence of 'Ginoza Hybrid No. 5' in Oct. 1988 and disinfested by placing individual $0.5-\mathrm{cm}$ inflorescence axis sections with the bract base and vegetative axillary bud in $0.5 \%$ sodium hypochlorite plus one drop of Tween20 (Sigma Chemical Co., St. Louis) per $100 \mathrm{ml}$ of diluted solution. After 10 rein, the axis was removed and trimmed to a cube $4 \mathrm{~mm}$ on each side, to include the bud, and placed in $0.25 \%$ sodium hypochlorite plus one drop of Tween 20 per $100 \mathrm{ml}$ of diluted solution for 15 rein, followed by a 5-min sterile water rinse. As evidenced by

\footnotetext{
Received for publication 1 Mar. 1993. Accepted for publication 6 Aug. 1993. Hawaii Institute of TropicalAgricultureandHumanResourcesJournal series no. 3809. We acknowledge John T. Kunisaki in whose laboratory this project was conducted. The costof publishing this paper was defrayed in part by the payment of page charges. Under postal regulations, this paper therefore must be hereby marked advertisement solely to indicate this fact.

'Undergraduate student.

${ }^{2}$ Professor
}

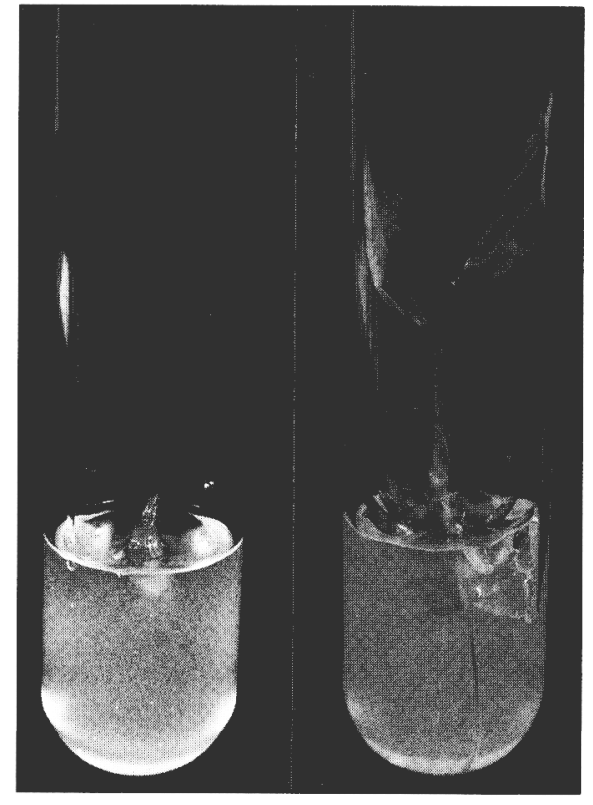

Fig.1.Bractaxil explant (left) and rooted shoot with basal buds (right) of A. purpurata 'Ginoza Hybrid No. 5' on agar medium.

$100 \%$ take, the disinfestation technique was adequate, with no visible contamination.

Ten of the disinfested buds were placed in a liquid medium consisting of one-half strength Murashige and Skoog ( $0.5 \times$ MS) formulation of basal salts and organics (Murashige and Skoog, 1962), 15\% coconut water, and 2\% sucrose, all adjusted to $\mathrm{pH}$ 5.6. Each bud was placed in a $22 \times 150$-mm culture tube containing $5 \mathrm{ml}$ of the liquid medium, sealed with foil, and placed on a rotary drum set at $2 \mathrm{rpm}$. The liquid medium was changed monthly for 5 months. The 10 remaining buds were placed in $22 \times 150-\mathrm{mm}$ culture tubes on 10 to $12 \mathrm{ml}$ of a similar medium solidified with $0.8 \%$ Difco Bacto-agm(Difco Lab., Detroit). Cultures were maintained at 25 to $27 \mathrm{C}$ under continuous light provided by Gro-lux fluorescent tubes (GTE Products Corp., Sylvania Lighting Center, Danvers, Mass.) at a photosynthetic photon flux (PPF) of $\approx 25 \mu \mathrm{mol} \cdot \mathrm{s}^{-1} \cdot \mathrm{m}^{-2}$.

Buds placed initially on solid medium did not develop as quickly as those placed in liquid medium. After 3 months on solid medium, these buds were transferred to liquid medium.
When the buds had elongated to $1 \mathrm{~cm}$, they were transferred to $22 \times 150$-mm culture tubes on an agar medium consisting of $0.5 \times$ MS plus $4.4 \mu \mathrm{M} N$-6-benzyladenine and $2 \%$ sucrose. Shoots arising from the bud axis continued to elongate, and 1 month later, the original explants were subculture onto fresh medium after removing rudimentary leaf sheaths and roots to permit development of new basal axillary shoots. After 2 weeks, basal axillary shoots emerged, averaging five per explant. These were excised 4 weeks later for further subculturing or rooting. Single shoots were rooted within 4 weeks on an agar-solidified $0.5 \times$ MS medium with $2 \%$ sucrose without supplemental growth regulators under the same environmental conditions as initial culture (Fig. 1). All shoots rooted, and the original shoot was recultured.

Rooted plantlets, $\approx 5 \mathrm{~cm}$ tall, were planted in a medium of 1 peat: 1 perlite: 1 vermiculite (by volume) in a plastic tray consisting of $5 \times$ $5 \times 7.5-\mathrm{cm}$ units. To prevent dessication, the tray was covered with a rigid plastic cover. The acclimatization environment was a laboratory shelf with $\approx 8 \mathrm{~h}$ of light daily from coolwhite fluorescent tubes (PPF. $15 \mu \mathrm{mol} \cdot \mathrm{s}^{-1} \cdot \mathrm{m}^{-2}$ and ambient temperatures of 23 to $25 \mathrm{C}$.

Developed plantlets 12 to $15 \mathrm{~cm}$ tall were transplanted to $15 \times 15 \times 12$-cm (1.4-liter) pots in a 1 soil : 1 peat : 1 perlite medium (by volume) and placed outdoors in a $30 \%$ shaded saranhouse where they were allowed to grow for 26 weeks. Thirty-four of the more than 100 plantlets were transplanted to a field at the Univ. of Hawaii's Waimanalo Research Station, where they bloomed in 1990-91, $\approx 20$ to 30 months after in vitro multiplication was initiated. Inflorescence shape and color and mature plant habit were identical with the original 'Ginoza Hybrid No. 5', as compared with plants at the original grower's field in 1992.

We have demonstrated that axillary vegetative buds on inflorescence bracts of $A$. purpurata cultivars that do not normally develop aerial offshoots can be cultured in vitro to increase desirable clones efficiently. No exceptional techniques are involved, and the source of explant is easily obtained and disinfested. Other Alpinia hybrids are being evaluated (Hirano, 1991) and may benefit from this rapid multiplication technique.

\section{Literature Cited}

Criley, R.A. 1988a. Development of Heliconia and Alpinia in Hawaii: Cultivar selection and culture. Acts Hort. 246:247-258.

Criley, R.A. 1988b. Propagation of tropical cut flowers: Strelitzia, Alpinia, and Heliconia. Acts Hort. 226:509-517.

Hirano, R.T. 1991. Alpinia purpurata (Vein.) K. Schum. in Hawaii. (The red and pink ginger) Bul. Heliconia Soc. Intl. 5(2):5-7.

Murashige, T. and F. Skoog. 1962. A revised medium for rapid growth and bioassay with tobacco tissue culture. Physiol. Plant. 15:473497. 